\title{
DigitalizaTiOn AND SiMULATION IN COINING
}

\author{
SKUNCA, M.; KERAN, Z. \& MATH, M.
}

Abstract: Coining as metal forming technology is known for its technological complexity and phenomenological problems. Development of $3 D$ scanners and FE codes, have enabled the simulation of coining using verse and obverse medal geometry. This includes simulation of details up to the scale where flow related phenomenon is observable. Modification of coin/medal geometry can be made during any of the phases in die production. This paper is trying to establish a connection between commercial FE code and $3 D$ digitalization in the field of minting. This results in potentially significant savings in tool production, allowing geometry modification, at any moment including the moment of artist creation of coin's obverse and reverse. Paper demonstrates the simulation of coining using digitized medal geometry, within the appropriate FE numerical code that enables the completion of virtual coining.

Key words: coining, 3D scan, FEM, metal forming, metal flow
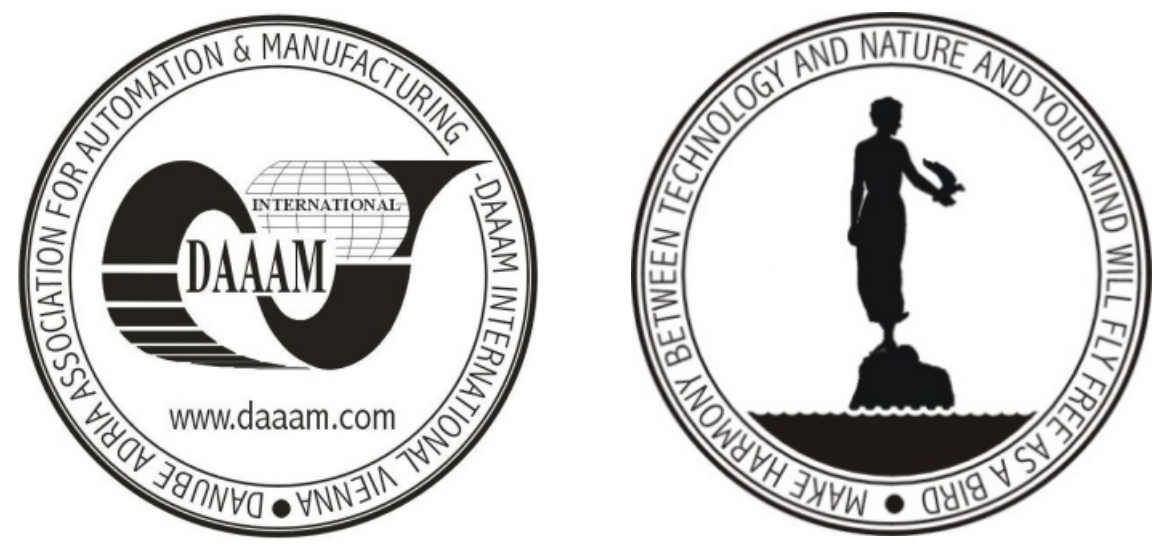

Authors' data: Dipl.-Ing. Skunca, M[arko]; Dipl.-Ing. Keran, Z[denka]; Univ.Prof. Dipl.-Ing. Math M[iljenko], Faculty of Mechanical Engineering and Naval Architecture, Ivana Lučića 5, HR-10000, Zagreb, Croatia, mskunca@fssb.hr, zkeran@fsb.hr, mmath@fsb.hr

This Publication has to be referred as: Skunca, M[arko]; Keran, Z[denka] \& Math M[iljenko] (2009). Digitalization and Simulation in Coining, Chapter 20 in DAAAM International Scientific Book 2009, pp. 177-186, B. Katalinic (Ed.), Published by DAAAM International, ISBN 978-3-901509-69-8, ISSN 1726-9687, Vienna, Austria DOI: $10.2507 /$ daaam.scibook.2009.20 